\title{
Longitudinal study on prenatal depression and anxiety during the COVID-19 pandemic
}

\author{
Hernán López-Morales ${ }^{1,2,3}$ (1) Macarena Verónica del-Valle ${ }^{1,2,3} \cdot$ María Laura Andrés $^{1,2,3} \cdot$ Rosario Gelpi Trudo $^{1,2,3}$. \\ Lorena Canet-Juric $^{1,2,3} \cdot$ Sebastián Urquijo ${ }^{1,2,3}$
}

Received: 4 April 2021 / Accepted: 2 June 2021 / Published online: 22 June 2021

(c) The Author(s), under exclusive licence to Springer-Verlag GmbH Austria, part of Springer Nature 2021

\begin{abstract}
Several studies have reported the negative impact of the COVID-19 pandemic context on mental health. Given that pregnant women constitute a vulnerable group, they may be at greater risk for developing psychopathological symptoms due to the confinement. The current study aimed to longitudinally analyze the presence and evolution of indicators of depression and anxiety in pregnant and non-pregnant women, and to identify the differential effects of social isolation or distancing measures on these groups. Participants were 105 pregnant and 105 non-pregnant Argentine adult women. They completed the Beck Depression Inventory-II, the State-Trait Anxiety Inventory, and closed-ended questions on sociodemographic factors, at four different times. Results showed a progressive increase in anxiety and depressive symptoms in the first 50 days of confinement in both groups, and a slight decrease after approximately 150 days. Pregnant women presented a more pronounced initial increase in symptoms, and a weaker decrease at the last wave, compared to the non-pregnant. Results suggest that the pandemic context produces a moderate negative early response and that the initial flexibilizations of sanitary measures (50 days) did not slow down the progression of symptoms (even less in pregnant women). In conclusion, being pregnant could be an extra risk factor for the development of psychopathological symptoms during this pandemic. The particular vulnerability of pregnant women and the associated potential negative effects both on them and on their offspring underline the importance of perinatal health policies aimed at prevention and treatment of possible future consequences.
\end{abstract}

Keywords Pregnancy $\cdot$ Lockdown $\cdot$ Prenatal depression $\cdot$ Prenatal anxiety $\cdot$ Stress

\section{Introduction}

With over 126 million cases worldwide and 2.7 million deaths (WHO 2021), the COVID-19 pandemic has become an unprecedented global event. This complex pandemic has led to the implementation of measures aimed at containing the spread of the disease. However, these measures are at the same time responsible for many negative effects, such as

Lorena Canet-Juric and Sebastián Urquijo contributed equally to this work.

Hernán López-Morales

hernanlopezmorales@gmail.com

1 Instituto de Psicología Básica, Aplicada y Tecnología (IPSIBAT), Mar del Plata, Argentina

2 Universidad Nacional de Mar del Plata (UNMDP), Mar del Plata, Argentina

3 Consejo Nacional de Investigaciones Científicas y Técnicas (CONICET), Mar del Plata, Argentina increased psychological distress (Brooks et al. 2020). Several studies (e.g., Benz et al. 2020; Daks et al. 2020; Salari et al. 2020; Wang et al. 2020) have already reported the negative impact on the mental health of the population. Most of them agree in highlighting the increase in psychological distress, depression, and anxiety. In addition, these psychopathological indicators appear to gradually increase in quantity and severity as the time of confinement lengthens (Brooks et al. 2020; Canet-Juric et al. 2020; Wang et al. 2020).

Compounding this scenario, belonging to vulnerable groups seems to have an even more negative effect (López Morales et al. 2021; Wilson et al. 2019). The pandemic context could exacerbate pre-existing conditions of inequality (Holmes et al. 2020). Women have shown the highest indicators of depression, anxiety, and stress (Fullana et al. 2020; Wang et al. 2020), especially those belonging to low- and middle-income countries (Canet-Juric et al. 2020), due to the financial and socio-environmental conditions of those countries (Gelaye et al. 2016). 
Even less attention has been paid to specific groups such as pregnant women. Pregnancy itself configures a special state of vulnerability in conventional contexts. Clinical indicators of depression and anxiety are the most common mental health problems experienced by pregnant women during the pre- and postnatal periods (Howard et al. 2014). These difficulties, in turn, could generate physical and mental problems in the offspring (Gemmill et al. 2019; Hoffman et al. 2016; Padmanabhan et al. 2016) and increase the risk of preterm birth or infant mortality (D'Onofrio et al. 2013). Recent studies suggest that, under normal circumstances, the prevalence of prenatal stress is around 20\% (Dennis et al. 2017), but this state of psychological vulnerability could be accentuated by the pandemic context (Berthelot et al. 2020). In addition, the pandemic context has introduced changes in medical routines during pregnancy, which further complicates the scenario (Roberton et al. 2020).

Recently, some studies have focused on the mental health of pregnant women and have reported an increase in depressive symptoms (Ceulemans et al. 2020; Dong et al. 2020; Durankuş and Aksu 2020; Perzow et al. 2021; Sun et al. 2020), anxiety symptoms (Hessami et al. 2020; Kotabagi et al. 2020; Liu et al. 2020), perceived distress (Berthelot et al. 2020), lower mental health (Kwasi Ahorsu et al. 2020), and moderate psychological impact due to confinement (Saccone et al. 2020). Zhou et al. (2020) have indicated that psychopathological symptoms increase as the number of cases of COVID infection or death increases. Also, Kotagabi et al. (2020) reported that anxiety and depressive indicators diminish when confinement is removed.

However, there is no record of studies that have longitudinally monitored this population throughout the lockdown (López Morales et al. 2021). Longitudinal monitoring of aspects such as depression and anxiety levels could yield relevant results for future planning of governmental strategies to stop the spread of the virus and its consequences (e.g., effect on mental health). In addition, comparing psychopathological indicators with the different governmental strategies (e.g., social isolation, recreational outings, social distancing) would provide evidence about the effect of these strategies on the mental health of this population.

Based on the above, the current study aims to longitudinally analyze the presence and course of anxiety and depression indicators in pregnant and non-pregnant women and to identify the differential effects on these groups of the isolation or distancing measures implemented. We hypothesize that the preexistence of conditions of vulnerability in women (in general) and in pregnant women (in particular) could constitute a risk factor for the development of some psychopathological disorder and increase the severity as the days of the pandemic pass, due to the effect of confinement.

\section{Methods}

\section{Participants}

The present study was carried out with 210 Argentine women: a pregnancy group with 105 pregnant women and a control group with 105 non-pregnant women. All participants were affected by some degree of social isolation measures during the COVID-19 pandemic. The age ranged from 18 to 45 years ( $m e a n=32.56 ; S D=4.71$ ). The groups had homogeneous sociodemographic characteristics (age, educational level, number of children, level of economic affectation due to the pandemic) (Table 1). Regarding the pregnancy group, only single pregnancies were included, in any week of gestation. The exclusion criteria were the use of psychotropic medication or steroids during pregnancy, the consumption of alcohol and/or illicit drugs, and having a psychopathological diagnosis prior to the pandemic. Sixteen women delivered during the study, so they were removed from the analyses ( $n$ at wave $3=207$; $n$ at wave $4=194$ ).

\section{Measures}

Depression symptoms The Spanish adaptation (Sanz et al. 2005; Sanz and Vázquez 2011) of the Beck Depression Inventory-II (BDI-II; Beck et al. 1996) was used. The BDIII is a self-report scale for the assessment of depressive symptoms. It consists of 21 items, each of which represents a symptom such as sadness, crying, appetite changes, guilt, and pessimism. The BDI-II has previously presented good reliability ( $\alpha=0.89$; Sanz et al. 2003) and validity in pregnant (Holcomb et al. 1996; Su et al. 2007) and non-pregnant (e.g., Beltrán et al. 2012; Sanz and Vázquez 1998) women. Beck et al.'s (1996) classification of levels of depression was also used (absent, minimum, mild, moderate, and severe). It is one of the most widely used scales internationally for the evaluation of depression during pregnancy (Nast et al. 2013). The scale has good internal consistency in studies with pregnant women (Cronbach's $\alpha$ was 0.87 ), which indicates good reliability (Bos et al. 2009). Cronbach's $\alpha$ for the BDI in the present study was 0.93 .

State anxiety The state-anxiety factor of the Spanish version (Spielberger et al. 1999) of the State-Trait Anxiety Inventory (STAI; Spielberger et al. 1970) was applied. The STAI is a self-report instrument. It consists of 40 items that assess anxiety as a state ( 20 items) and as a trait (20 items). The participant is asked to answer in a range from 0 to 3 . Considering the aim of the present study, only the state-anxiety subscale was applied. The STAI has previously showed good 
Table 1 Sociodemographic variables in both groups and chi-square

\begin{tabular}{|c|c|c|c|c|c|c|}
\hline Variable & & $\begin{array}{l}\text { Pregnant women } \\
(n=105)\end{array}$ & $\begin{array}{l}\text { Non-pregnant } \\
\text { women } \\
(n=105)\end{array}$ & Total sample & $X^{2}$ & $Z$ \\
\hline \multirow[t]{2}{*}{ Age } & Mean & 32.49 & 32.54 & 32.51 & - & -0.107 \\
\hline & SD & 4.71 & 4.71 & 4.70 & & \\
\hline \multirow[t]{5}{*}{ Geographic region } & Pampeana region & $79.0 \%$ & $71.6 \%$ & $75.4 \%$ & 0.84 & - \\
\hline & Cuyo region & $8.6 \%$ & $9.8 \%$ & $9.2 \%$ & & \\
\hline & Patagonia region & $5.7 \%$ & $10.8 \%$ & $8.2 \%$ & & \\
\hline & Northwest region & $5.7 \%$ & $3.9 \%$ & $4.8 \%$ & & \\
\hline & Northeast region & $1.0 \%$ & $3.9 \%$ & $2.4 \%$ & & \\
\hline \multirow[t]{2}{*}{ Phase during wave 4} & SPCI & $33.3 \%$ & $41.2 \%$ & $37.8 \%$ & 1.36 & - \\
\hline & SPCD & $67.7 \%$ & $58.8 \%$ & $63.2 \%$ & & \\
\hline \multirow{5}{*}{$\begin{array}{l}\text { Level of economic affectation } \\
\text { due to the pandemic }\end{array}$} & No & $36.2 \%$ & $38.2 \%$ & $37.2 \%$ & 1.61 & - \\
\hline & Few & $22.9 \%$ & $25.5 \%$ & $24.2 \%$ & & \\
\hline & Some & $23.8 \%$ & $21.6 \%$ & $22.7 \%$ & & \\
\hline & Much & $5.7 \%$ & $5.9 \%$ & $5.8 \%$ & & \\
\hline & Very much & $11.4 \%$ & $7.8 \%$ & $9.7 \%$ & & \\
\hline \multirow[t]{7}{*}{ Educational level } & Postgrad & $34.3 \%$ & $32.4 \%$ & $33.3 \%$ & 1.20 & - \\
\hline & University (complete) & $34.3 \%$ & $35.3 \%$ & $34.8 \%$ & & \\
\hline & University (incomplete) & $26.7 \%$ & $27.5 \%$ & $27.1 \%$ & & \\
\hline & Secondary (complete) & $3.8 \%$ & $4.9 \%$ & $4.3 \%$ & & \\
\hline & Secondary (incomplete) & $1.0 \%$ & $0 \%$ & $0.5 \%$ & & \\
\hline & Primary (complete) & $0 \%$ & $0 \%$ & $0 \%$ & & \\
\hline & Primary (incomplete) & $0 \%$ & $0 \%$ & $0 \%$ & & \\
\hline \multirow[t]{3}{*}{ Number of previous children } & 0 & $59.0 \%$ & $56.9 \%$ & $58.3 \%$ & 0.99 & - \\
\hline & 1 & $35.2 \%$ & $37.3 \%$ & $36.4 \%$ & & \\
\hline & 2 & $4.8 \%$ & $5.9 \%$ & $5.3 \%$ & & \\
\hline \multirow[t]{2}{*}{ Pychotherapy } & No & $75.2 \%$ & $81.4 \%$ & $78.3 \%$ & 0.54 & - \\
\hline & Yes & $24.7 \%$ & $18.6 \%$ & $21.8 \%$ & & \\
\hline
\end{tabular}

$X^{2}=$ chi-square $/ Z=$ Mann-Whitney $U$ test. All values were $>05$

$S P C I$, Social, Preventive and Compulsory Isolation; $S P C D$, Social, Preventive and Compulsory Distancing

reliability ( $\alpha=0.84$ to 0.93 ; Riquelme and Casal 2011) and validity in pregnant (Gunning et al. 2010) and non-pregnant (Riquelme and Casal 2011) women. The STAI has been used for research purposes with both pregnant ( $\alpha=0.83$ to 0.72 ; Delgado et al. 2016) and non-pregnant samples. It is even the most widely used scale in studies of pregnant women, presenting the best validity and reliability indicators (Nast et al. 2013). Cronbach's $\alpha$ for the STAI in the present study was 0.86 .

Sociodemographic features Closed-ended questions were applied to explore age, educational level, number of children, geographic region, isolation measure (phase), economic affectation due to the pandemic, and if they receive psychotherapy. Exclusively in pregnant women, two additional features were also considered: pregnancy weeks and presence of diseases or medical complications (Table 2).

\section{Procedure}

The survey was uploaded on Google Forms and disseminated through social networks by means of a snowball sampling procedure. Participants answered four surveys at different times during the pandemic (Fig. 1). The first survey (wave 1) was conducted between the second and the fifth days of quarantine, and provided the baseline scores for the study. Wave 2 took place 12 to 21 days after the SPCI has started; thus, it assessed the early, immediate outcomes of the containment measures. Wave 3 of the study was conducted after 47 to 51 days of restrictions; thus, its objective was to evaluate the effects of the first outings and flexibilizations. Finally, the fourth survey (wave 4) was administered 138 to 147 days after the start of the restrictions. At this moment, distinctions have to be made between different regions: while some areas-including the Metropolitan 
Table 2 Specific characteristics of the group of pregnant women

\begin{tabular}{|c|c|c|c|c|c|c|}
\hline \multirow[t]{2}{*}{ Variable } & & \multicolumn{5}{|c|}{ Pregnant women } \\
\hline & & $\begin{array}{l}\text { Time } 1 \\
(\mathrm{n}=105)\end{array}$ & $\begin{array}{l}\text { Time } 2 \\
(\mathrm{n}=105)\end{array}$ & $\begin{array}{l}\text { Time } 3 \\
(n=102)\end{array}$ & $\begin{array}{l}\text { Time } 4 \\
(\mathrm{n}=89)\end{array}$ & Total \\
\hline \multirow[t]{2}{*}{ Weeks of pregnancy } & Mean & 17.82 & 19.82 & 22.47 & 31.5 & 22.89 \\
\hline & SD & 9.01 & 9.01 & 8.01 & 6.50 & 8.13 \\
\hline \multirow[t]{3}{*}{ Trimester of pregnancy } & First trimester & $38.5 \%$ & $27.7 \%$ & $15.0 \%$ & $0 \%$ & $20.30 \%$ \\
\hline & Second trimester & $41.5 \%$ & $44.6 \%$ & $53.3 \%$ & $36.0 \%$ & $43.85 \%$ \\
\hline & Third trimester & $20.0 \%$ & $27.7 \%$ & $31.7 \%$ & $64.0 \%$ & $35.85 \%$ \\
\hline \multirow[t]{11}{*}{ Diseases or medical complications } & Heavy bleeding & - & - & - & - & $2.9 \%$ \\
\hline & Fluid retention & - & - & - & - & $9.8 \%$ \\
\hline & Nausea or vomiting in excess & - & - & - & - & $19.6 \%$ \\
\hline & Drop of $5 \mathrm{~kg}$ or more & - & - & - & - & $2.9 \%$ \\
\hline & Increase of $12 \mathrm{~kg}$ or more & - & - & - & - & $11.8 \%$ \\
\hline & Infections & - & - & - & - & $2.9 \%$ \\
\hline & Hypertension & - & - & - & - & $1.0 \%$ \\
\hline & Thyroid problems & - & - & - & - & $8.8 \%$ \\
\hline & Gestational diabetes & - & - & - & - & $2.0 \%$ \\
\hline & Blood incompatibility & - & - & - & - & $1.0 \%$ \\
\hline & Other diseases & - & - & - & - & $3.9 \%$ \\
\hline
\end{tabular}

Area of Buenos Aires-were still under the same isolation measures as they were during wave 3 , most of the provinces were already in a social distancing phase.

\section{Data analysis}

Descriptive statistics were calculated for the entire sample and for both groups (Table 3). The chi-square test was used to analyze sociodemographic differences between groups (educational level, number of children, and level of economic affectation due to the pandemic). Mann-Whitney $U$ tests were applied to compare age in both groups. No variable was found to differ between the two groups $(p>0.05)$ (Table 1).

The mixed repeated measures ANOVA statistic was used to test the effect of the pandemic over time (intra-subject

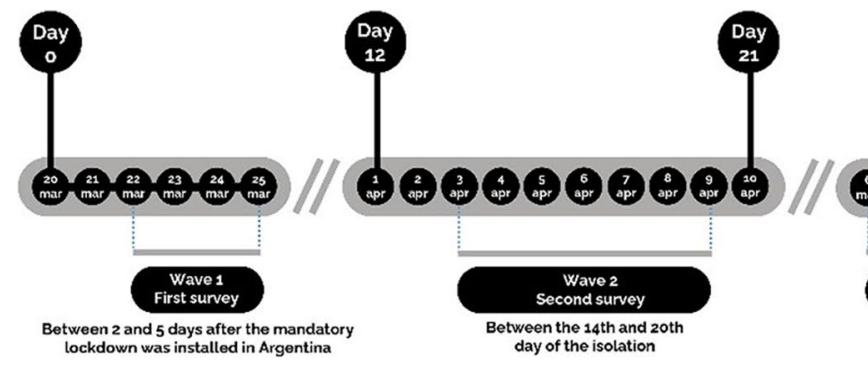

Fig. 1 Development of lockdown in Argentina and days when the surveys were administered. The timeline marks the beginning of the mandatory quarantine decreed by the Argentine State (March 20), and the development of the different stages of the process until August 12. In the lower part of the figure, the ranges of days in which the surveys were answered by the participants are graphed. Note: To mitigate the impact of the pandemic, the Argentine government established social isolation measures, which are organized in phases according to their degree of flexibility. First, on March 20, 2020, Social, Preventive and Compulsory Isolation (SPCI) was declared. Phase 1 of SPCI consisted of a strict quarantine throughout the national territory, which only allowed mobility for basic purchases and essential workers. Phase 2 ("administrated isolation") started on April 18, adding new

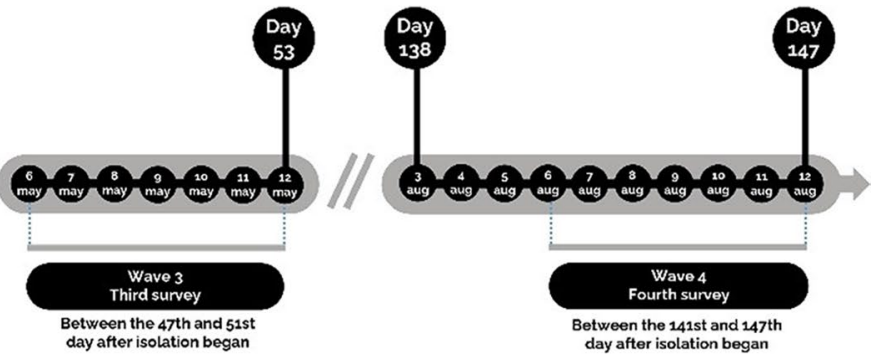

exceptions to the restrictions. Phase 3 ("geographical segmentation") was established on April 26, allowing for short recreational outings and the opening of non-essential shops in certain regions, according to the epidemiological status of each province and department. On June 4, the government declared the start of Social, Preventive and Compulsory Distancing (SPCD) in 18 provinces where the viral circulation was minimal. SPCD enabled the mobility of up to $75 \%$ of the population, with protocols of social distancing and hygiene measures. As of August 13, approximately $85 \%$ of the population was under SPCD measures, while the remaining 15\% (living in areas with high population density, such as the Metropolitan Area of Buenos Aires) was still affected by SPCI 
Table 3 Descriptive statistics of the administered tests

\begin{tabular}{|c|c|c|c|c|c|c|c|c|c|c|c|c|c|}
\hline \multirow[t]{2}{*}{ Variable } & & \multicolumn{4}{|c|}{ Pregnant women } & \multicolumn{4}{|c|}{ Non-pregnant women } & \multicolumn{4}{|l|}{ Total } \\
\hline & & Wave 1 & Wave 2 & Wave 3 & Wave 4 & Wave 1 & Wave 2 & Wave 3 & Wave 4 & Wave 1 & Wave 2 & Wave 3 & Wave 4 \\
\hline \multirow[t]{8}{*}{ Depression } & Mean & 8.71 & 10.02 & 15.42 & 14.49 & 7.92 & 9.06 & 10.83 & 8.66 & 8.32 & 9.55 & 13.15 & 11.60 \\
\hline & SD & 6.08 & 6.43 & 8.50 & 7.45 & 4.53 & 4.86 & 6.79 & 6.32 & 5.37 & 5.71 & 8.02 & 7.49 \\
\hline & Absent & $57.8 \%$ & $52.0 \%$ & $27.7 \%$ & $24.8 \%$ & $60.6 \%$ & $54.5 \%$ & $43.0 \%$ & $61.8 \%$ & $59.2 \%$ & $53.3 \%$ & $35.3 \%$ & $42.8 \%$ \\
\hline & Minimum & $20.6 \%$ & $17.3 \%$ & $18.8 \%$ & $19.0 \%$ & $26.3 \%$ & $23.2 \%$ & $28.0 \%$ & $17.6 \%$ & $23.4 \%$ & $20.3 \%$ & $23.4 \%$ & $18.3 \%$ \\
\hline & Mild & $12.7 \%$ & $23.5 \%$ & $20.8 \%$ & $25.7 \%$ & $11.1 \%$ & $16.2 \%$ & $19.0 \%$ & $10.8 \%$ & $11.9 \%$ & $19.8 \%$ & $19.9 \%$ & $18.3 \%$ \\
\hline & Moderate & $8.8 \%$ & $7.1 \%$ & $19.8 \%$ & $22.9 \%$ & $2.0 \%$ & $6.1 \%$ & $6.0 \%$ & $3.9 \%$ & $5.5 \%$ & $6.6 \%$ & $12.9 \%$ & $13.5 \%$ \\
\hline & Severe & $0 \%$ & $0 \%$ & $12.9 \%$ & $6.7 \%$ & $0 \%$ & $0 \%$ & $4.0 \%$ & $2.9 \%$ & $0 \%$ & $0 \%$ & $8.5 \%$ & $4.8 \%$ \\
\hline & Moderate + Severe & $8.8 \%$ & $7.1 \%$ & $32.7 \%$ & $29.6 \%$ & $2.0 \%$ & $6.1 \%$ & $10.0 \%$ & $6.8 \%$ & $5.5 \%$ & $6.6 \%$ & $21.4 \%$ & $18.3 \%$ \\
\hline \multirow[t]{2}{*}{ Anxiety } & Mean & 22.66 & 22.52 & 28.10 & 26.12 & 21.51 & 21.69 & 23.97 & 21.18 & 22.09 & 22.11 & 26.04 & 23.66 \\
\hline & SD & 9.48 & 8.76 & 9.60 & 6.93 & 8.44 & 8.20 & 9.27 & 6.93 & 8.98 & 8.49 & 9.63 & 7.85 \\
\hline
\end{tabular}

factor) and inclusion of the pregnant or non-pregnant group (inter-subject factor) on depression and anxiety (dependent variables). In cases where the W Mauchnik leads to rejection of the sphericity test, the Greenhouse-Geisser correction was used. The Bonferroni statistic was used for the adjustment of multiple comparisons.

All tests were two-sided and $p$-values less than 0.05 were considered statistically significant. Statistical analyses were performed using IBM SPSS Statistics 24.

\section{Results}

Depression Results of mixed repeated measures ANOVA demonstrated a significant effect of time ( $F$ $\left.(2.69,517.36)=51.77, p<0.001, \eta_{p}{ }^{2}=0.21\right)$ and an interaction effect of time-groups $\left(F_{(2.69,517.36)}=18.53, p<0.001\right.$, $\eta_{p}{ }^{2}=0.09$ ) (Table 4) (Fig. 2A). A significant effect of the group factor (inter-subject) was also demonstrated ( $F$ $\left.(1,192)=15.30, p=0.001, \eta_{p}{ }^{2}=0.07\right)$ (Table 4). In the total sample, significant differences were observed between the four measures $(p<0.01)$, evidencing a progressive increase until the third wave, and a significant decrease after about

Table 4 Results of repeated measures ANOVA for depression, anxiety, and negative and positive effects

\begin{tabular}{llrll}
\hline Variable & Effect & \multicolumn{3}{c}{ Repeated measures } \\
\cline { 3 - 5 } & & \multicolumn{1}{c}{ F } & $p$-value & $\eta_{p}{ }^{2}$ \\
\hline \multirow{2}{*}{ Depression } & Time & 80.51 & 0.001 & 0.29 \\
& Group & 7.16 & 0.008 & 0.03 \\
& Time-group & 14.78 & 0.001 & 0.07 \\
Anxiety & Time & 50.34 & 0.001 & 0.20 \\
& Group & 3.16 & 0.08 & 0.01 \\
& Time-group & 8.02 & 0.001 & 0.04 \\
\hline
\end{tabular}
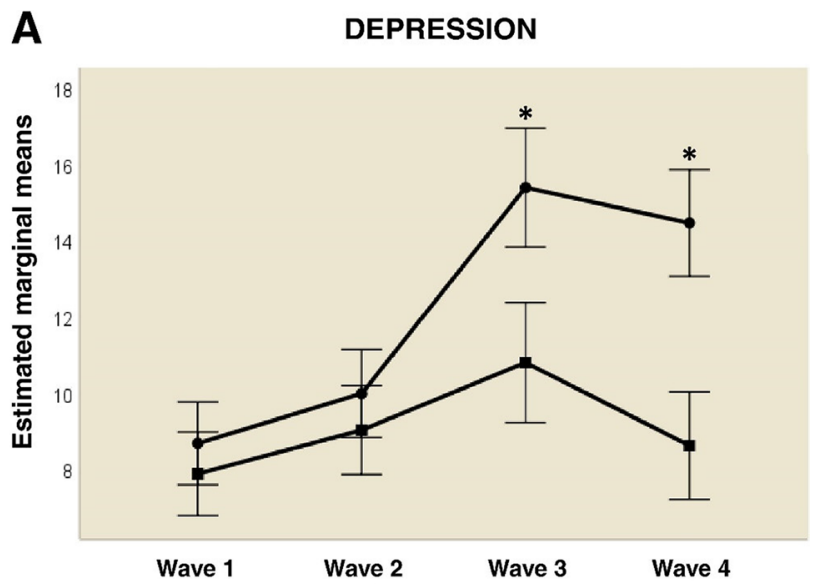

B ANXIETY

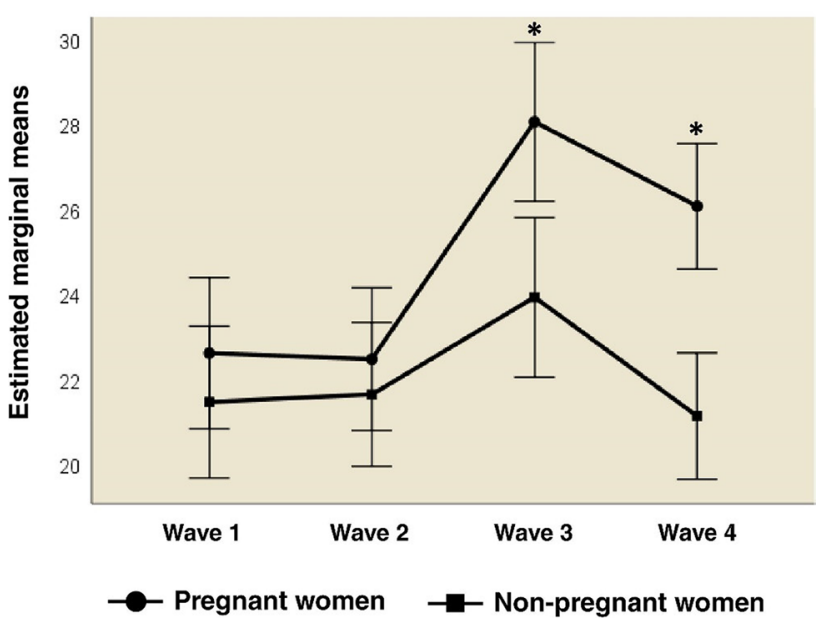

Fig. 2 Comparison of the adjusted mean of the psychopathological variables in both groups, during the four phases of the study. The figure compares the adjusted means for (A) depression and (B) anxiety in pregnant women (circles) and non-pregnant women (squares), during the four phases of the study (wave 1 , wave 2 , wave 3 , and wave 4). $* p<0.01 /$ error bars $\pm 2 \mathrm{SD}$ 
150 days (fourth wave). According to the post hoc tests for paired comparisons with Bonferroni correction, there were no statistically significant differences in depression between the groups at wave 1 , nor at wave 2 . At waves 3 and 4 , however, significant differences were observed between pregnant women and non-pregnant women $(p<0.01)$. Furthermore, intragroup analyzes with Bonferroni correction showed that pregnant women presented significant increase until wave 3, after which the rates remain similar. Regarding non-pregnant women, a significant increase was found between waves 2 and 3, while during wave 4 the depressive symptoms decreased, being homogeneous to those recorded in waves 1 and 2.

Anxiety Results of mixed repeated measures ANOVA demonstrated a significant effect of time $\left(F_{(2.87,577.25)}=33.54\right.$, $\left.p<0.001, \eta_{p}{ }^{2}=0.14\right)$ and interaction effect of timegroups $\left(F_{(2.87,577.25)}=10.41, p<0.001, \eta_{p}{ }^{2}=0.05\right)($ Table 4) (Fig. 2B). A significant effect of the group factor (intersubject factor) was identified $\left(F_{(1,201)}=6.60, p=0.011\right.$, $\eta_{p}{ }^{2}=0.032$ ) (Table 4). In the total sample, significant differences were found between the measures at waves 1 and 2 with respect to waves 3 and $4(p<0.01)$. According to the post hoc tests for paired comparisons with Bonferroni correction, there were no statistically significant differences in anxiety between the groups at wave 1, nor at wave 2 . At waves 3 and 4 , however, significant differences were observed between pregnant women and non-pregnant women $(p<0.01)$. Furthermore, intragroup analyzes with Bonferroni correction showed that pregnant women showed significant differences only at waves 3 and $4(p<0.001)$. In non-pregnant women, however, significant differences were only identified at wave 3 .

Sociodemographic features Results of mixed repeated measures ANOVA demonstrated that none of the sociodemographic variables had significant effects on depression and anxiety, in any of the temporal measures of longitudinal design $(p<0.05)$ (Table 5).

\section{Discussion}

This study aimed to investigate the presence and evolution of psychopathological indicators of depression and anxiety in a sample of pregnant and non-pregnant women. Pregnancy could be an aggravating factor for the appearance of psychopathological symptoms, as already reported in previous pandemics (Lee et al. 2006; Lohm et al. 2014). The implications of virus restriction policies could have serious effects on the mental health of the population and of pregnant women in particular (Cava et al. 2005; Khan et al. 2020; Lee et al. 2006).
Table 5 Results of repeated measures ANOVA for the dependent variables (depression and anxiety) with sociodemographic variables as inter-subject factors

\begin{tabular}{lllll}
\hline Variable & Effect & \multicolumn{3}{l}{ Repeated measures } \\
\cline { 3 - 5 } Depression & $\begin{array}{l}\text { Level of economic } \\
\text { affectation due to the }\end{array}$ & 0.661 & 0.801 & 0.017 \\
& $\quad$ & & \\
& pandemic & & & \\
& Phase & 1.362 & 0.256 & 0.007 \\
& Age & 0.383 & 0.867 & 0.004 \\
& Educational level & 0.632 & 0.793 & 0.013 \\
& Number of children & 1.441 & 0.206 & 0.015 \\
Anxiety & Psychotherapy & 0.699 & 0.630 & 0.007 \\
& Level of economic & 1.138 & 0.320 & 0.028 \\
$\quad$ affectation due to the & & & \\
$\quad$ pandemic & & & \\
& Phase & 1.393 & 0.286 & 0.007 \\
& Age & 1.879 & 0.072 & 0.028 \\
& Educational level & 1.513 & 0.120 & 0.030 \\
& Number of children & 0.682 & 0.657 & 0.007 \\
& Psychotherapy & 0.198 & 0.972 & 0.002 \\
\hline
\end{tabular}

Despite the importance of this issue, and although several cross-sectional studies have been published (e.g., Berthelot et al. 2020; Dong et al. 2020; Durankuş and Aksu 2020; Liu et al. 2020; Saccone et al. 2020; Sun et al. 2020; Zhou et al. 2020), to date, there are no longitudinal studies that have monitored the evolution of anxiety and depression indicators in this population. In addition, most of the cross-sectional studies have been conducted in high-income countries, with few studies in low- and middle-income countries (i.e., López Morales et al. 2021; Medina-Jimenez et al. 2020; ParraSaavedra et al. 2020).

The present study reveals a progressive increase in anxiety and depressive symptoms in the first 50 days of confinement in both pregnant and non-pregnant women. The results also indicate a slight decrease in symptoms after approximately 150 days (wave 4). These data are consistent with those reported by previous longitudinal studies of the general population that have also highlighted the progressive increase on depression and anxiety (Benz et al. 2020; Goularte et al. 2021; Shi et al. 2020). However, when comparing pregnant and non-pregnant women, the former presented a more pronounced increase in depression and anxiety symptoms over time (waves 1-3) and the decrease in wave 4 was weaker.

In relation to depressive symptomatology, our study reports that as isolation is extended, so are the indicators of depression, at least until the third wave. For pregnant women in particular, $32.7 \%$ of the participants indicated a moderate to severe level of depression at wave 3 . These rates decrease to $29.6 \%$ within 150 days (wave 4 ). These 
results are higher than the prevalence for developing countries (19-25\%; Gelaye et al. 2016) and even higher than reported for developed countries (7-15\%; Woody et al. 2017). Cross-sectional studies during the COVID-19 pandemic have indicated a similar significant increase in prenatal depression indicators compared to pre-COVID-19 prevalence (Ceulemans et al. 2020; Lebel et al. 2020; Parra-Saavedra et al. 2020; Wu et al. 2020).

The repeated measures mixed ANOVA demonstrated a significant effect of time and a time-group interaction on depression. The differences between both groups are more pronounced after the first 50 days, where the highest and most significant values are recorded, although this same trend is maintained in the fourth wave of the study. Therefore, being pregnant could be an extra risk factor for the development of depressive symptomatology during this pandemic. As previously reported, social isolation could lead to loss of social support, sadness about being separated from loved ones, change in daily routines, and restriction of usual liberties (Cava et al. 2005; Lee et al. 2006). These conditions could lead to an increase in prenatal depression in the medium term. In conclusion, the usual risk of developing prenatal depression (Gelaye et al. 2016) is compounded by a set of contextual variables due to the pandemic that generates a greater vulnerability to psychopathology. Studies that have analyzed pre- and post-COVID-19 cohorts have highlighted the significant increase in depression indicators, which reinforces these statements (Berthelot et al. 2020; Zhou et al. 2020).

The results demonstrated that anxiety increases over time up to wave 3 in both pregnant and non-pregnant women. However, for pregnant women, the increase is more pronounced. According to these findings, some researchers have reported high rates of anxiety in pregnant women during the COVID-19 pandemic (e.g., Ceulemans et al. 2020; Hessami et al. 2020; Moyer et al. 2020). The perinatal period can itself lead to emotional complications such as distress, fear, or anxiety (Liu et al. 2016; Liu and Tronick 2014), but it seems that the COVID-19 pandemic conditions are likely to produce additional perinatal distress (Berthelot et al. 2020). At wave 4, anxiety levels decrease for both groups. It is possible that, over time, people slowly adapt to the new living conditions, reducing the perceived distress (Ayuso et al. 2020). However, in the present study, while non-pregnant women's anxiety drops to levels similar to the ones at waves 1 and 2, in pregnant women, this decrease is weaker, and anxiety remains higher than that reported in waves 1 and 2 . It is possible that the suspension of medical care and prenatal control routines (Roberton et al. 2020) could generate negative effects on the mental health of pregnant women, as it could increase concerns about pregnancy, childbirth, and postpartum (Thapa et al. 2020). Also, Hessami et al.
(2020) have reported that the uncertainty generated by the possible effects of COVID-19 infection on delivery and fetal growth or the potential risk of vertical mother-tofetus transmission could increase distress.

In contrast to previous research, our study did not identify significant effects of sociodemographic variables, such as age (Wu et al. 2020), financial problems (Zhang and Ma 2020), or educational level (Dong et al. 2020). However, the sample of our study is quite homogeneous: most of the women reported a high educational level and a low financial affectation. This could explain the null effect reported.

We previously mentioned the importance of analyzing the effect of governmental measures to reduce the spread of the virus on mental health. We observed a moderate early response to confinement (waves 1 and 2), which peaked abruptly at 50 days (wave 3). At this time, the Argentine government began to flexibilize social isolation, allowing daily recreational outings (Canet-Juric et al. 2020). These, apparently, were not enough to slow down the progression of depression and anxiety and, at the same time, this effect was even less effective in pregnant women. The results of the 4th wave show a slight improvement in the mental health of the participants, except for the depression symptoms of the pregnant women, which remained homogeneous to those recorded at wave 3 . However, no differences were observed between areas in SPCI and SPCD, so this decrease cannot be attributed solely to the modifications of the confinement. On the other hand, in the case of pregnant women, it may be that the approaching of the delivery date (and associated concerns) may have sustained the elevated levels of depression and anxiety.

The issue addressed in this study is of crucial importance given the underlying vulnerability of pregnant women. The scenario worsens even more if one considers the effects of prenatal depression and anxiety on the development of the fetus or on the postnatal infant. Maternal psychopathology increases the risk of preterm birth, decreases prenatal care, reduces effective mother-child bonding, and could even generate lower cognitive and emotional development in children (Glover 2015; Madigan et al. 2018; Verbeek et al. 2015; Yonkers et al. 2017). For such reasons, the particular vulnerability of pregnant women and the associated potential negative effects both on them and on their offsprings underline the importance of perinatal health policies aimed at prevention and treatment of possible future consequences.

It is important to highlight that the study has some limitations. The sample is made up of women with a high educational level, favorable economic conditions, low negative financial impact from the pandemic, and predominantly living in most populated urban centers, which limits the scope of the results. Some of these characteristics (for example, educational level and negative financial impact) contrast with the true reality of the Argentine population, so it will 
be necessary to recruit a more representative sample for subsequent studies.

Funding The following study was supported by the Ministry of Science, Technology and Innovation of the Argentine Nation "Articulation Program and Federal Strengthening of Capacities in Science and Technology COVID-19",

\section{Declarations}

Ethics approval This study was reviewed and approved by the Bioethics Committee of the National University of Mar del Plata.

Conflict of interest The authors declare no competing interests.

\section{References}

Ayuso L, Requena F, Jiménez-Rodriguez O, Khamis N (2020) The effects of COVID-19 confinement on the Spanish family: adaptation or change? J Comp Fam Stud 51:274-287. https://doi.org/10. 3138/jcfs.51.3-4.004

Beck AT, Steer RA, Brown GK (1996) Beck Depression Inventory-II. The Psychological Corporation, San Antonio

Beltrán MDC, Freyre MÁ, Hernández-Guzmán L (2012) El Inventario de Depresión de Beck: Su validez en población adolescente. Terapia Psicológica 30:5-13. https://doi.org/10.4067/S0718-48082 012000100001

Benz A, Meier M, Bentele UU et al (2020) Early life adversity, dispositional mindfulness, and longitudinal stress experience during the COVID-19 pandemic. https://doi.org/10.31234/osf.io/5kt6z

Berthelot N, Lemieux R, Garon-Bissonnette J et al (2020) Uptrend in distress and psychiatric symptomatology in pregnant women during the coronavirus disease 2019 pandemic. Acta Obstet Gynecol Scand 99:848-855. https://doi.org/10.1111/aogs.13925

Bos SC, Pereira AT, Marques M, Maia B, Soares MJ, Valente J, Azevedo MH (2009) The BDI-II factor structure in pregnancy and postpartum: two or three factors? Eur Psychiatry 24:334-340. https://doi.org/10.1016/j.eurpsy.2008.10.003

Brooks SK, Webster RK, Smith LE et al (2020) The psychological impact of quarantine and how to reduce it: rapid review of the evidence. Lancet 395:14-20. https://doi.org/10.1016/S0140-6736(20) 30460-8

Canet-Juric L, Andrés ML, del Valle M et al (2020) A longitudinal study on the emotional impact cause by the COVID-19 pandemic quarantine on general population. Front Psychol 11:565688. https://doi.org/10.3389/fpsyg.2020.565688

Cava MA, Fay KE, Beanlands HJ et al (2005) The experience of quarantine for individuals affected by SARS in Toronto. Public Health Nurs 22:398-406. https://doi.org/10.1111/j.0737-1209. 2005.220504.x

Ceulemans M, Hompes T, Foulon V (2020) Mental health status of pregnant and breastfeeding women during the COVID- 19 pandemic: a call for action. Int J Gynaecol Obstet. https://doi.org/10. 1002/ijgo. 13295

D'Onofrio BM, Class QA, Rickert ME et al (2013) Preterm birth and mortality and morbidity: a population-based quasi-experimental study. JAMA Psychiat 70:1231-1240. https://doi.org/10.1001/ jamapsychiatry.2013.2107

Daks JS, Peltz JS, Rogge RD (2020) Psychological flexibility and inflexibility as sources of resiliency and risk during a pandemic: modeling the cascade of COVID-19 stress on family systems with a contextual behavioral science lens. J Contextual Behav Sc 18:16-27. https://doi.org/10.1016/j.jcbs.2020.08.003

Delgado AM, Freire ADB, Wanderley ELS, Lemos A (2016) Analysis of the construct validity and internal consistency of the state-trait anxiety inventory (STAI) state-anxiety (S-anxiety) scale for pregnant women during labor. Rev Bras Ginecol Obstet 38:531-537. https://doi.org/10.1055/s-0036-1593894

Dennis CL, Falah-Hassani K, Shiri R (2017) Prevalence of antenatal and postnatal anxiety: systematic review and meta-analysis. $\mathrm{Br}$ J Psychiatry 210:315-323. https://doi.org/10.1192/bjp.bp.116. 187179

Dong H, Hu R, Lu C et al (2020) Investigation on the mental health status of pregnant women in China during the Pandemic of COVID19. Arch Gynecol Obstet 303:463-469. https://doi.org/10.1007/ s00404-020-05805-x

Durankuş F, Aksu E (2020) Effects of the COVID-19 pandemic on anxiety and depressive symptoms in pregnant women: a preliminary study. J Matern Fetal Neonatal Med 1-7.https://doi.org/10. 1080/14767058.2020.1763946

Fullana MA, Hidalgo-Mazzei D, Vieta E et al (2020) Coping behaviors associated with decreased anxiety and depressive symptoms during the COVID-19 pandemic and lockdown. J Affect Disord 275:80-81. https://doi.org/10.1016/j.jad.2020.06.027

Gelaye B, Rondon MB, Araya R et al (2016) Epidemiology of maternal depression, risk factors, and child outcomes in low-income and middle-income countries. Lancet Psychiatry 3:973-982. https:// doi.org/10.1016/S2215-0366(16)30284-X

Gemmill A, Catalano R, Casey JÁ et al (2019) Association of preterm births among US latina women with the 2016 presidential election. JAMA Netw Open 2:e197084-e197084. https://doi.org/10. 1001/jamanetworkopen.2019.7084

Glover V (2015) Prenatal stress and its effects on the fetus and the child: possible underlying biological mechanisms. In: Antonelli MC (ed) Perinatal programming of neurodevelopment. Springer, New York, pp 269-283

Goularte JF, Serafim SD, Colombo R et al (2021) COVID-19 and mental health in Brazil: psychiatric symptoms in the general population. J Psychiatr Res 132:32-37. https://doi.org/10.1016/j.jpsyc hires.2020.09.021

Gunning MD, Denison FC, Stockley CJ, Ho SP, Sandhu HK, Reynolds RM (2010) Assessing maternal anxiety in pregnancy with the State-Trait Anxiety Inventory (STAI): issues of validity, location and participation. J Reprod Infant Psychol 28:266-273. https:// doi.org/10.1080/02646830903487300

Hessami K, Romanelli C, Chiurazzi M, Cozzolino M (2020) COVID19 pandemic and maternal mental health: a systematic review and meta-analysis. J Matern Fetal Neonatal Med. https://doi.org/10. 1080/14767058.2020.1843155

Hoffman MC, Mazzoni SE, Wagner BD, Laudenslager ML (2016) Measures of maternal stress and mood in relation to preterm birth. Obstet Gynecol 127:545-552. https://doi.org/10.1097/AOG. 0000000000001287

Holcomb WL, Stone LS, Lustman PJ, Gavard JA, Mostello DJ (1996) Screening for depression in pregnancy: characteristics of the Beck Depression Inventory. Obstet Gynecol 88:1021-1025. https://doi. org/10.1016/S0029-7844(96)00329-8

Holmes EA, O'Connor RC, Perry VH et al (2020) Multidisciplinary research priorities for the COVID-19 pandemic: a call for action for mental health science. Lancet Psychiatry 7:547-560. https:// doi.org/10.1016/S2215-0366(20)30168-1

Howard LM, Molyneaux E, Dennis CL et al (2014) Nonpsychotic mental disorders in the perinatal period. Lancet 384:1775-1788. https://doi.org/10.1016/S0140-6736(14)61276-9

Khan S, Peng L, Siddique R et al (2020) Impact of COVID-19 infection on pregnancy outcomes and the risk of maternal-to-neonatal 
intrapartum transmission of COVID-19 during natural birth. Infect Control Hosp Epidemiol 41:748-750. https://doi.org/10.1017/ice. 2020.84

Kotabagi P, Fortune L, Essien S et al (2020) Anxiety and depression levels among pregnant women with COVID-19. Acta Obstet Gynecol Scand 99:953-954. https://doi.org/10.1111/aogs.13928

Kwasi Ahorsu D, Imani V, Lin C et al (2020) Associations between fear of COVID-19, mental health, and preventive behaviours across pregnant women and husbands: an actor-partner interdependence modelling. Int J Ment Health Addict. https://doi. org/10.1007/s11469-020-00340-x

Lebel C, MacKinnon A, Bagshawe M et al (2020) Elevated depression and anxiety among pregnant individuals during the COVID-19 pandemic. J Affect Disord 277:5-13. https://doi. org/10.1016/j.jad.2020.07.126

Lee DTS, Sahota D, Leung TN et al (2006) Psychological responses of pregnant women to an infectious outbreak: a case-control study of the 2003 SARS outbreak in Hong Kong. J Psychosom Res 61:707-713. https://doi.org/10.1016/j.jpsychores.2006.08.005

Liu CH, Tronick E (2014) Prevalence and predictors of maternal postpartum depressed mood and anhedonia by race and ethnicity. Epidemiol Psychiatr Sci 23:201-209. https://doi.org/10. 1017/S2045796013000413

Liu CH, Giallo R, Doan SN et al (2016) Racial and ethnic differences in prenatal life stress and postpartum depression symptoms. Arch Psychiatr Nurs 30:7-12. https://doi.org/10.1016/j. apnu.2015.11.002

Liu H, Liu F, Li J et al (2020) Clinical and CT imaging features of the COVID-19 pneumonia: focus on pregnant women and children. J Infect 80:e7-e13. https://doi.org/10.1016/j.jinf.2020. 03.007

Lohm D, Flowers P, Stephenson N et al (2014) Biography, pandemic time and risk: pregnant women reflecting on their experiences of the 2009 influenza pandemic. Health 18:493-508. https://doi.org/ $10.1177 / 1363459313516135$

López Morales H, del Valle M, Canet Juric L et al (2021) Mental health of pregnant women during the COVID-19 pandemic: a longitudinal study. Psychiatry Res 295:113567. https://doi.org/10.1016/j. psychres.2020.113567

Madigan S, Oatley H, Racine N et al (2018) A meta-analysis of maternal prenatal depression and anxiety on child socioemotional development. J Am Acad Child Adolesc Psychiatry 57:645-657. e8. https://doi.org/10.1016/j.jaac.2018.06.012

Medina-Jimenez V, Bermudez-Rojas MDLL, Murillo-Bargas $\mathrm{H}$ et al (2020) The impact of the COVID-19 pandemic on depression and stress levels in pregnant women: a national survey during the COVID-19 pandemic in Mexico. J Matern Fetal Neonatal Med. https://doi.org/10.1080/14767058.2020.1851675

Moyer CA, Compton SD, Kaselitz E, Muzik M (2020) Pregnancyrelated anxiety during COVID-19: a nationwide survey of 2740 pregnant women. Arch Womens Ment Health 23:757-765. https:// doi.org/10.1007/s00737-020-01073-5

Nast I, Bolten M, Meinlschmidt G, Hellhammer DH (2013) How to measure prenatal stress? A systematic review of psychometric instruments to assess psychosocial stress during pregnancy. Paediatr Perinat Epidemiol 27:313-322. https://doi.org/10.1111/ppe. 12051

Padmanabhan V, Cardoso RC, Puttabyatappa M (2016) Developmental programming, a pathway to disease. Endocrinology 157:13281340. https://doi.org/10.1210/en.2016-1003

Parra-Saavedra M, Villa-Villa I, Pérez-Olivo J et al (2020) Attitudes and collateral psychological effects of COVID-19 in pregnant women in Colombia. Int J Gynaecol Obstet 151:203-208. https:// doi.org/10.1002/ijgo.13348
Perzow SE, Hennessey EMP, Hoffman MC et al (2021) Mental health of pregnant and postpartum women in response to the COVID19 pandemic. J Affect Disord Rep 4:100123. https://doi.org/10. 1016/j.jadr.2021.100123

Riquelme AG, Casal GB (2011) Actualización psicométrica y funcionamiento diferencial de los ítems en el State Trait Anxiety Inventory (STAI). Psicothema 23:510-515

Roberton T, Carter ED, Chou VB et al (2020) Early estimates of the indirect effects of the COVID-19 pandemic on maternal and child mortality in low-income and middle-income countries: a modelling study. Lancet Glob Health 8:e901-e908. https://doi.org/10. 1016/S2214-109X(20)30229-1

Saccone G, Florio A, Aiello F et al (2020) Psychological impact of coronavirus disease 2019 in pregnant women. Am J Obstet Gynecol 223:293-295. https://doi.org/10.1016/j.ajog.2020.05.003

Salari N, Hosseinian-Far A, Jalali R et al (2020) Prevalence of stress, anxiety, depression among the general population during the COVID-19 pandemic: a systematic review and metaanalysis. Glob Health 16:1-11. https://doi.org/10.1186/ s12992-020-00589-w

Sanz J, Vázquez C (1998) Fiabilidad, validez y datos normativos del Inventario para la Depresión de Beck. Psicothema 10:303-318

Sanz J, Vázquez C (2011) Adaptación Española del Inventario para Depresión de Beck-II (BDI-II). Manual. Pearson, Madrid

Sanz J, Perdigón AL, Vázquez C (2003) Adaptación española del Inventario para la Depresión de Beck-II (BDI-II): 2. Propiedades psicométricas en población general. Clín Salud 14:249-280

Sanz J, García-Vera MP, Espinosa R et al (2005) Adaptación española del Inventario para la Depresión de Beck-II (BDI-II): 3. Propiedades psicométricas en pacientes con trastornos psicológicos. Clin Salud 16:121-142

Shi L, Lu ZA, Que JY et al (2020) Prevalence of and risk factors associated with mental health symptoms among the general population in China during the coronavirus disease 2019 pandemic. JAMA Netw Open 3(7):e2014053. https://doi.org/10.1001/jamanetwor kopen.2020.14053

Spielberger CD, Gorsuch RL, Lushene RE (1970) Manual for the State-Trait Anxiety Inventory. Consulting Psychologists Press, Palo Alto

Spielberger CD, Gorsuch RL, Lushene RE, Cubero NS (1999) STAI: Cuestionario de Ansiedad Estado-Rasgo. TEA ediciones, Madrid

Su KP, Chiu TH, Huang CL, Ho M, Lee CC, Wu PL, Pariante CM (2007) Different cutoff points for different trimesters? The use of Edinburgh Postnatal Depression Scale and Beck Depression Inventory to screen for depression in pregnant Taiwanese women. Gen Hosp Psychiatry 29:436-441. https://doi.org/10.1016/j.genho sppsych.2007.05.005

Sun G, Wang F, Cheng Y (2020) Perinatal depression during the COVID-19 epidemic in Wuhan, China. SSRN Electron J. https:// doi.org/10.2139/ssrn.3576929

Thapa SB, Mainali A, Schwank SE, Acharya G (2020) Maternal mental health in the time of the COVID-19 pandemic. Acta Obstet Gynecol Scand 99:817-818. https://doi.org/10.1111/aogs.13894

Verbeek T, Arjadi R, Vendrik JJ et al (2015) Anxiety and depression during pregnancy in Central America: a cross-sectional study among pregnant women in the developing country Nicaragua. BMC Psychiatry 15:292. https://doi.org/10.1186/ s12888-015-0671-y

Wang C, Pan R, Wan X et al (2020) A longitudinal study on the mental health of general population during the COVID-19 epidemic in China. Brain Behav Immun 87:40-48. https://doi.org/10.1016/j. bbi.2020.04.028 
Wilson S, McCloughen A, Parr J, Jackson D (2019) "If you are homeless you are welcome here": social obligations for the homeless and socially disadvantaged. J Clin Nurs 28:2721-2723. https:// doi.org/10.1111/jocn.14851

Woody CA, Ferrari AJ, Siskind DJ et al (2017) A systematic review and meta-regression of the prevalence and incidence of perinatal depression. J Affect Disord 219:86-92. https://doi.org/10.1016/j. jad.2017.05.003

World Medical Organization (2021) Weekly operational update on COVID-19 - 29 March 2021. https:// www. who.int/publications/m/item/weekly-opera tional-update-on-covid-19---29-march-2021

Wu Y, Zhang C, Liu H et al (2020) Perinatal depressive and anxiety symptoms of pregnant women along with COVID-19 outbreak in China. Am J Obstet Gynecol 223:240e1-240e9. https://doi.org/10. 1016/j.ajog.2020.05.009
Yonkers KA, Gilstad-Hayden K, Forray A, Lipkind HS (2017) Association of panic disorder, generalized anxiety disorder, and benzodiazepine treatment during pregnancy with risk of adverse birth outcomes. JAMA Psychiat 74:1145-1152. https://doi.org/10.1001/ jamapsychiatry.2017.2733

Zhang Y, Ma ZF (2020) Psychological responses and lifestyle changes among pregnant women with respect to the early stages of COVID-19 pandemic. Int J Soc Psychiatry. https://doi.org/10. $1177 / 0020764020952116$

Zhou Y, Shi H, Liu Z et al (2020) The prevalence of psychiatric symptoms of pregnant and non-pregnant women during the COVID19 epidemic. Transl Psychiatry 10:319. https://doi.org/10.1038/ s41398-020-01006-x

Publisher's note Springer Nature remains neutral with regard to jurisdictional claims in published maps and institutional affiliations. 